\title{
Heatwave Vulnerability Assessment of Nursing Homes Based on Dynamic Simulations
}

\author{
Dóra Szagri ${ }^{1}$, Balázs Nagy ${ }^{1}$, Zsuzsa Szalay $^{1}$ \\ ${ }^{1}$ Budapest University of Technology and Economics, Faculty of Civil Engineering, Department of \\ Construction Materials and Technologies, Müegyetem rkp. 3. K.I.85, 1111 Budapest, Hungary
}

\begin{abstract}
The frequency and magnitude of summer heatwaves has significantly increased in Hungary in recent years, and research shows that we can expect the same level of temperature anomalies in the near future. For this paper we performed dynamic simulations of nursing homes to examine the effect of building types and construction methods on summer overheating. Potential factors influencing the overheating risk of a building include the design, building number of storeys, roof shape, building materials, glazing ratio and shading. Taking into account these factors, we used a whole-building simulation software to compare the building types and the internal temperatures in the rooms, considering different user behaviour. Several vulnerability maps and models were developed in recent years and most of them are based on meteorological and demographic data. Our research approaches the issue from the point of view of building structures, taking into account the building itself and its environment in detail in case of a particularly exposed group. The results can be used to assess the most critical buildings and construction types and contribute to assessing the heat vulnerability index of Budapest.
\end{abstract}

\section{Introduction}

In the case of Hungary, a heatwave is defined as the daily average temperature staying above $26.6{ }^{\circ} \mathrm{C}$ for 3 consecutive days according to the interpretation of the National Directorate General for Disaster Management (BM OKF 2018). When the temperature exceeds $25^{\circ} \mathrm{C}$ at maximum, "summer day" term is used. The number of summer days experienced each year in Hungary has increased by 8 since the start of the last century and the number of days with heatwaves by 5 . According to climatic models, the number of summer days is expected to increase significantly in the future: from 2021 to 2050, this will mean an increase of more than 16 to 20 days on average per year (Lakatos et al. 2012). On the basis of the available literature, the number of deaths also increases during heatwaves: on the one hand, due to the effect of elevated temperatures of the body (Bunker et al. 2016) and indirectly, for example, the number of road accidents increases (Wu, Zaitchik, and Gohlke 2018). The risk of heat-related death varies with age, gender, and cause of death, but a similar pattern emerges for each city (Ishigami et al. 2008). In the case of heatwaves, environmental factors and geographic location are not the only key points, but also the response to the heatwave and the timing of heatwaves: in the case of the first heatwave of the year, the risk of heat stroke is five times higher than during later ones (Liss et al. 2017). In addition, it is worth examining the adaptability of people to evolving climate conditions, because people are becoming less and less sensitive to heat-related deaths (Arbuthnott et al. 2016).

Based on climate forecasts, many researchers have set out to investigate the overheating of buildings. In the future, heating energy consumption will decrease, while the demand for cooling energy will increase (Dodoo and Gustavsson 2016). Overheating can be observed for all types of buildings where no special intervention has taken place. However, the effectiveness of different methods depends on the type of building, increased air-change rate and shading usually helps prevent overheating. The thermal insulation and HVAC system is also an important aspect of overheating (Pyrgou et al. 2017; Fosas et al. 2018). In particular, high-level thermal insulation leads to more frequent temperature observation over $26{ }^{\circ} \mathrm{C}$. Among the buildings of different designs (different amount of thermal insulation, existence of HVAC system), the insulated building without HVAC system shows the effect of long-lasting heat, where the internal temperatures exceed $35^{\circ} \mathrm{C}$. Buildings that meet the minimum thermal insulation requirements prescribed by regulations can be disadvantageous to the internal temperature if there is no climatization in the building. Building materials that have a higher thermal conductivity and heat capacity, allow easy storage of daytime heat, slow down the rate of night cooling.

The main aim of our research was to evaluate the overheating of two buildings in Budapest, analysing different structural modifications and user behaviour (ventilation and shading methods). Several literature sources have already investigated the effect of external temperatures on the mortality in elderly homes (Marmor 1978; Holstein et al. 2005; Klenk, Becker, and Rapp 2010). Nursing homes were selected in the analysis, because its inhabitants belong to the age group, which is one of the most vulnerable to heatwaves.

\section{Methodology}

The research focused on the older population in more detail due to the potential health issues and the different thermoregulation system of elderly people. Therefore, we created a database of nursing homes in Budapest, and then we carried out a survey using a questionnaire. The main purpose was to evaluate the state of the elderly homes in 
Budapest and the methods which are used against summer overheating. The response rate was $41 \%, 30$ homes filled out the forms. Based on the results of the survey, it can be seen that the type, condition and age of the elderly homes in Budapest show high diversity. Most of the buildings were built between 1946-1979 and 30\% of the homes after 1990. In $66 \%$ of the buildings energy-related retrofits (thermal insulation, modernization of the heating system, fenestration replacement) have taken place in the last 10 years. Shading solutions can be found in $80 \%$ of the buildings, which is quite a good rate. The air-conditioning of nursing homes is not typical in Hungary.

From this sample, we selected two characteristic buildings for further analysis. The analysed buildings can accommodate 131 and 67 people, which are representative based on the size of the homes. The results of the questionnaire helped to determine the equipment of the current building stock and some input data needed for the simulation. In our research, the overheating of buildings was evaluated according to the $\mathrm{ODH}_{26}$ indicator (Artmann, Manz, and Heiselberg 2008). $\mathrm{ODH}_{26}$ is the number of hours with temperature above $26{ }^{\circ} \mathrm{C}$. It determines not only the duration, but also the extent of the indicated overheating (unit of measure $\mathrm{Kh} / \mathrm{a}$ ). The dynamic simulation of buildings was performed with the validated WUFI Plus software (Antretter et al. 2011) in which the geometric design of the building was given manually. During the tests, the simulation was run for 2 years with hourly resolution. The first year was the initialization period, which is necessary to exclude from the evaluation due to initial conditions of the building constructions (e.g. temperature, moisture content). The initial parameters were set according to typical built-in conditions. After the initialization, the results of the second year are closer to reality, therefore only the last year was taken into account in the evaluation.

\section{Analysed buildings}

The analysed buildings are located on both the Buda and Pest side of the city and have different building structures and construction times. The first building (Fig. $1-$ left side) was built with prefabricated slag concrete blocks around the 1960s. The building was retrofitted in the 2000s, with façade and plinth wall thermal insulation, furthermore the doors and windows were replaced. The second building (Fig. 1 - right side) consists of thick walls made from brick. This building is much older than the previous one. It was built before the 1900s. Over the years, the building has only undergone façade repairs, but it was not insulated as it is under monument protection. In most cases only floor plans were available for the buildings, so the layer composition was based on on-site measurements and the typical constructions of the era. The thermal transmittance of the walls was $0.37 \mathrm{~W} / \mathrm{m}^{2} \mathrm{~K}$ in the first case, and $0.52-0.91 \mathrm{~W} / \mathrm{m}^{2} \mathrm{~K}$ in second case depending on the structural thickness.

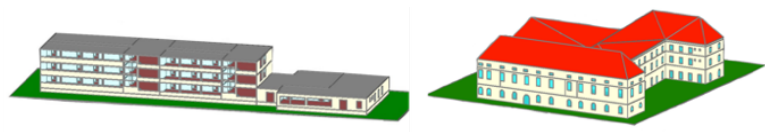

Figure 1: 3-dimensional model of the analysed buildings
In case of the zone distribution we wanted to focus on the rooms where the elderly live, so the buildings were divided according to this need. In the first case the building was divided into 5 parts on every level (Fig. 2).

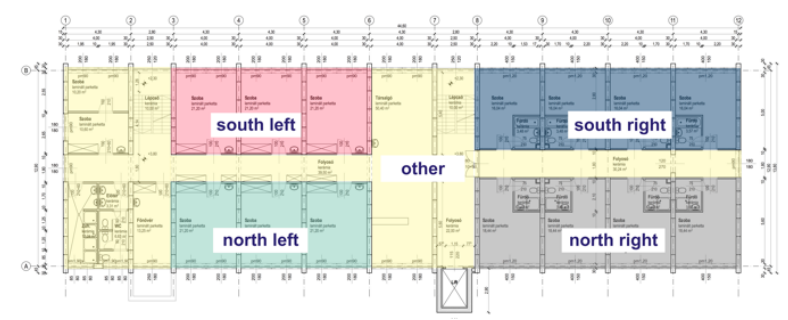

Figure 2: zone distribution of building 1

In the case of the second building, the elderly section is located on the 1st floor, so this part of the building has been divided into a total of 10 zones (Fig. 3). After the simulations, the internal air and operative temperature values were retrieved for these zones.

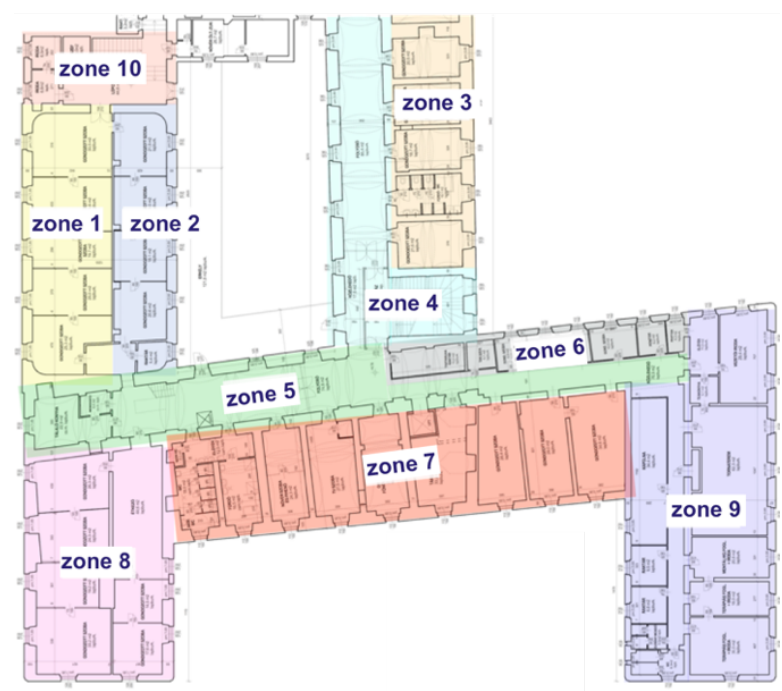

Figure 3: zone distribution of building 2

\section{Boundary conditions}

The weather file used for the simulation is based on data generated from different stations around Budapest. As part of the research, we also examined the effects of the future climate. For this, we used the weather generated by the IPCC A2 scenario for 2050 and 2100. Figure 4 shows the air temperature in Budapest during a given year. The values rise remarkably in all future climates, the average annual temperature is $12.38^{\circ} \mathrm{C}$ in $2018,14.38{ }^{\circ} \mathrm{C}$ in 2050 and $16.44{ }^{\circ} \mathrm{C}$ in 2100 , which is approximately a $2{ }^{\circ} \mathrm{C}$ increase per year.

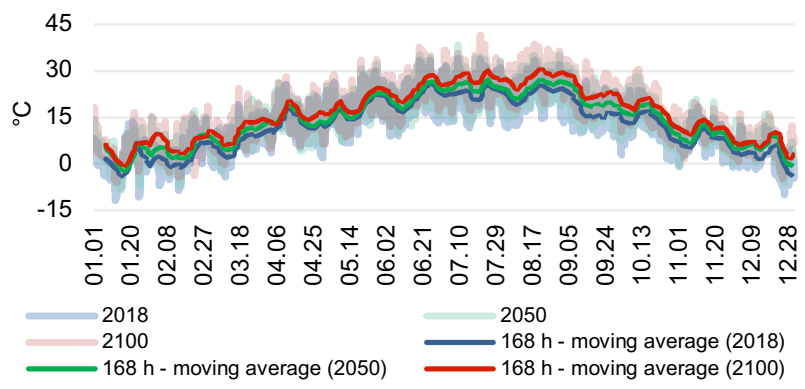

Figure 4: external temperature (2018, 2050, 2100) 
In the case of internal design conditions, the minimum temperature was set to $20^{\circ} \mathrm{C}$. The infiltration was set to $0.1 \mathrm{1} / \mathrm{h}$ with an air exchange rate of 0.5 , while in the summer, an elevated air exchange $(21 / \mathrm{h})$ was used during the night hours (between $8 \mathrm{pm}$ and $6 \mathrm{am}$ ). For internal loads, we also took into account the function of the zones (care room, office, attic, etc.). The values were individually set, taking into account the number of people in the zones and the activities taken. Shading solutions were assumed in accordance with reality (building 1 parts on the southern side, building 2 - no shading) with "reduce overheating" setting in the software, where the sunscreen device was closed as long as the maximum temperature was exceeded.

\section{Examined scenarios}

During the simulations, we also examined retrofitting measures and different user habits, where several suggestions were made to avoid summer overheating. Compared to the basic model (REF), the summer nighttime air change rates were raised to $41 / \mathrm{h}(4 \mathrm{ACH})$ and 6 $1 / \mathrm{h}(6 \mathrm{ACH})$. In the selection of these values, it was a consideration to keep in mind the values of the Hungarian regulation (3-6 1/h) and it is in accordance with other literature data (Seth et al. 2008; Atkinson et al. 2009). In case of shading, three different methods were used according to the software: limit radiation value (LRV), reduce overheating (REF) and schedule (SCHED) options. With limit radiation value, the device will stay closed as long as the solar radiation exceeds the maximum radiation defined previously. In the last option, an individual schedule was given, where the shutters were gradually lowered in the summer. Wherever possible, additional thermal insulation was applied on the full surface (INS) or only on the topmost slab (SLAB). For the optimized model (OPT), the most favourable user habits were considered, with the best results in shading and ventilation, e.g. higher air change rates at night, less ventilation during daytime in the summer. Finally, in the case of the reference and optimized model, we also examined the impact of the future climate on the overheating of buildings.

\section{Results}

The $\mathrm{ODH}_{26}$ indicator of the models show to what extent the chosen methods help to reduce the number of overheated hours. The results of the first building are shown in Figure 5.

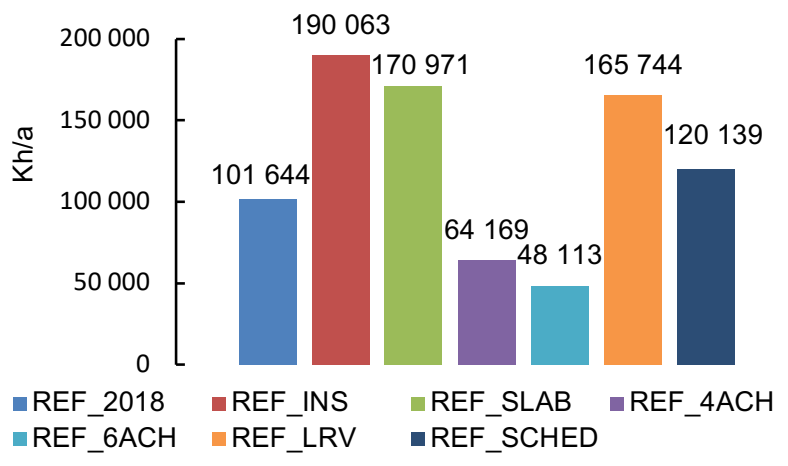

Figure 5: $\mathrm{ODH}_{26}$ indicators of building 1
The $\mathrm{ODH}_{26}$ value was extremely high for the reference building, which was also influenced by the fact that the maximum temperature reached $34{ }^{\circ} \mathrm{C}$ in the building (the indicator includes not only the number of the overheated hours but also the extent of the heat). The value of the indicator in the case of the additional thermal insulation of the building increases significantly: by $68 \%$ using only additional slab insulation, and by $88 \%$ with full insulation. If we compare the indicators, it can be seen that the greatest improvement was achieved by the increase in the summer night-time ventilation. This elevated ventilation $(41 / \mathrm{h}, 61 / \mathrm{h})$ resulted in $37 \%$ and $53 \%$ decrease in the $\mathrm{ODH}_{26}$ value, respectively. Furthermore, the optimally chosen shading method also plays a major role in reducing the number of overheated hours.

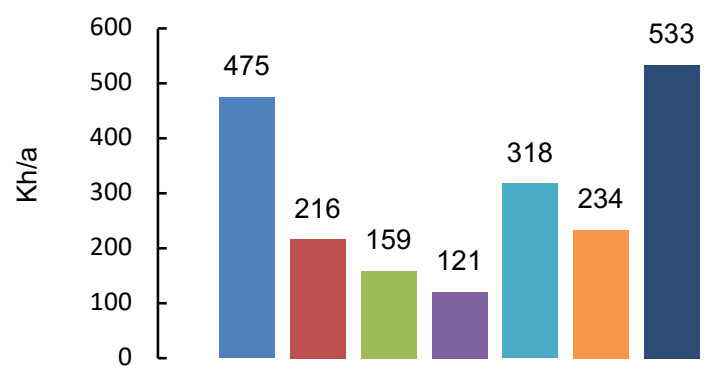

$\square \mathrm{REF} \backsim 4 \mathrm{ACH} \backsim 6 \mathrm{ACH} \backsim \mathrm{SCHED} \backsim \mathrm{LRV} \backsim \mathrm{REDUCE} \backsim \mathrm{INS}$

Figure 6: $\mathrm{ODH}_{26}$ indicators of building 2

In the case of the second building, the number of overheated hours was generally much lower. The temperature of the internal air in some zones occasionally reaches $28^{\circ} \mathrm{C}$, but the average maximum is around $26^{\circ} \mathrm{C}$, which was the threshold of the indicator. Similarly to the previous building, the best results are achieved partly by increasing the night-time ventilation, and the shading system has a greater role here, as the original building does not have any. The thermal insulation of the building slightly increases the overheating - that is, it behaves similarly to the first building.

\section{Future scenarios}

Examining the first structure, the $\mathrm{ODH}_{26}$ values in 2050 will increase by 1.5 times. It can be seen that in 2100 , the value of the indicator is 2.5 times higher without cooling system in the building, which clearly indicates that the quality of the building should be improved in the future.

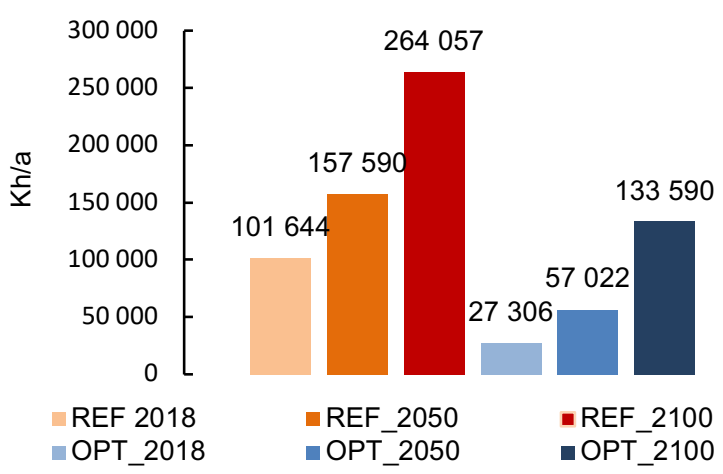

Figure 7: $\mathrm{ODH}_{26}$ indicators of future scenarios (building 1) 
Considering the optimized version (OPT), in which we neglected the additional thermal insulation of the building and only the optimal shading/ventilation was used, a significant reduction could be achieved for the three climate files. By examining the current weather data, the values were reduced by $75 \%$, while in 2100 a reduction of nearly $50 \%$ was achieved.

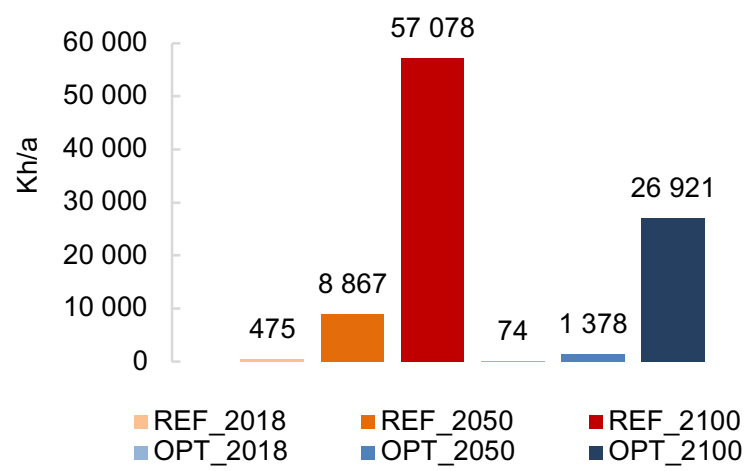

Figure 8: $\mathrm{ODH}_{26}$ indicators of future scenarios (building 2)

Figure 8 shows the number of $\mathrm{ODH}_{26}$ values of the original (REF) and optimized (OPT) models in case of the second building. While in the first two cases the optimized user habits showed a decrease of $84 \%$, in 2100 only a $52 \%$ reduction can be achieved, i.e. in this case it may be justified to consider the use of a cooling system.

The decrease in the values is roughly even between the zones. Only in the case of the attic is it smaller, since there has been no change in the night-time ventilation rate as in the regular zones.

\section{Discussion}

In general, the first building has a higher risk of overheating. In the case of this building, the temperature on the 1st floor was the hottest (Figure 9). One of the reasons for this may be night-time radiation through the uninsulated roof, the 2nd level can cool down more easily during the night. With regard to the overheating of buildings, not only the building structures and geometry, but also the shading solution has an effect on the internal temperature.

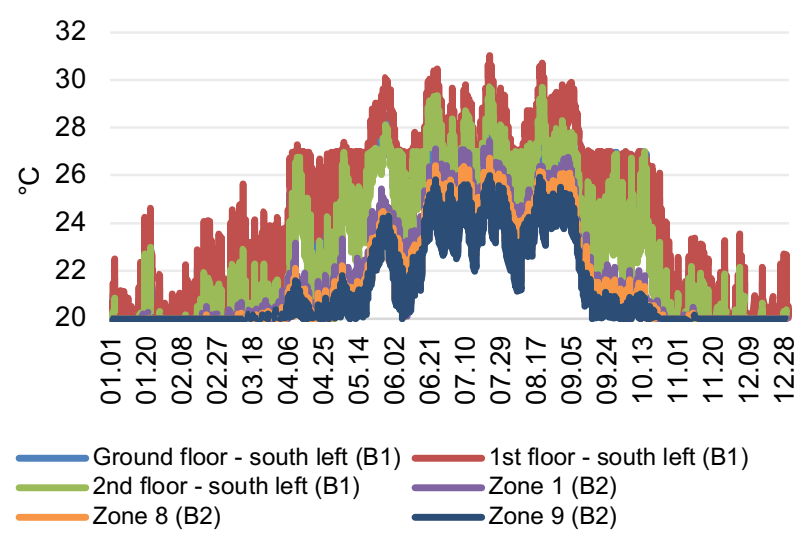

Figure 9: internal air temperatures in building 1 (B1) and building 2 (B2)
In addition, the shading factor used (vegetation in front of the facade and geometry of pillars) also plays a role in the differences: large-scale vegetation not only improves the living conditions of the inhabitants, but also plays a role in reducing internal air temperature.

Based on the simulations, the value of the $\mathrm{ODH}_{26}$ indicator in case of additional thermal insulation increases significantly. This is mainly because the building is easily warmed up by prolonged warm days and it is difficult to cool down, the value of the night air-change rate is not sufficient to significantly reduce the internal temperature. Another important feature is that the initial warming of the 1st floor becomes less after the application of thermal insulation, in that case the second floor will be the hottest part of the building. A similar phenomenon can be observed if thermal insulation is used only on the roof slab. In these cases, the application of the thermal insulation prevents the radiation to the night sky.

The negative effect of thermal insulation on warming shows that if the ventilation and shading strategy is properly chosen in the case of the fully insulated building, the value of the $\mathrm{ODH}_{26}$ indicator can be reduced by $10 \%$. With thermal insulation and proper user behaviour (ventilation and shading), a considerable reduction can be achieved in case of free-running buildings. Furthermore, it should not be overlooked that the thermal insulation of the building can significantly reduce heating energy consumption in the winter.

In case of the 2 nd building the $\mathrm{ODH}_{26}$ value in the original building is $475 \mathrm{Kh} /$ year, which is really low compared to the first one. The value observed is partly due to the orientation of the building and the fact that it is made of very thick structures with a large heat capacity, so that it can warm up relatively slowly.

The temperature of the internal air in some zones occasionally reaches $28^{\circ} \mathrm{C}$, but the average maximum is around $26^{\circ} \mathrm{C}$. The value of the internal temperature varies depending on the zone: the ground floor of the building had the lowest temperature, as expected, and on the $1 \mathrm{st}$ floor, the hottest zone was Zone 1, Zone 3, Zone 6, and Zone 8, all of which are care rooms.

However, analysing future climates, it can be seen that the warming can be a problem, as the indicator value is 8867 $\mathrm{Kh} /$ year in 2050 and $56078 \mathrm{Kh} /$ year in 2100, respectively, which is an enormous rise compared to the current weather.

If we look at two zones as a priority (Zone 3 and Zone 8) for future climate files (Figure 10), we can observe how much the rooms are warming up during the year. For Zone 8 using the weather of 2100 , the maximum temperature can reach $31^{\circ} \mathrm{C}$, which is $5^{\circ} \mathrm{C}$ increase (originally was 26 ${ }^{\circ} \mathrm{C}$ ) but can be seen even at 2050 at least $2{ }^{\circ} \mathrm{C}$ rise in internal temperature values. By highlighting Zone 1, Zone 3 and Zone 7 (Figure 11), it can be seen that in the case of the optimized model, the internal air temperature was reduced to a visible extent. With proper operating habits, a $1.5-2{ }^{\circ} \mathrm{C}$ reduction was achieved. 


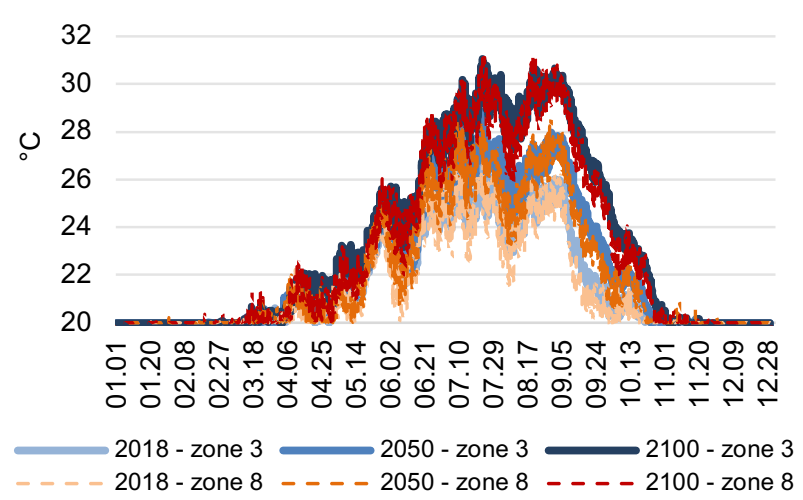

Figure 10: internal air temperature for future scenarios (building 2)

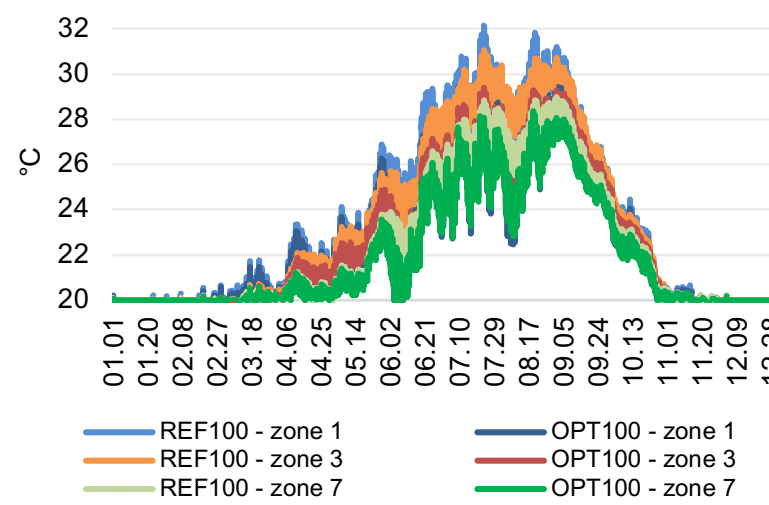

Figure 11: internal air temperature for future scenarios (building 2) with optimised user behaviour

In total, this version also shows the biggest decrease due to changed user habits. However, it should not be overlooked that design changes are also needed on the 1st floor, which may be one aspect of future renovations.

The rooms are not connected to a corridor, so there is no possibility of creating fast and intense cross ventilation. It is definitely an interesting question what kind of air exchange can be achieved with the current design, and what design can achieve optimal results while retaining the current capacity (number of inhabitants). This was outside the scope of this research.

\section{Future utilization of results}

The research is part of the evaluation of overheating of the Hungarian building stock with the future goal of creating a heat vulnerability map, in which we consider the dynamic simulations based on building typology.

An analysis has been made among European countries (Kendrovski et al. 2017), where the aim was to quantify the possible future impact of heat on population mortality, but there is no HVI (Heat Vulnerability Index) map available for Hungary yet. In general, excess mortality is measured in daily data, but it may be interesting to examine these data in more detail at hourly resolution (Guo et al. 2014). To reduce the negative effects of heat, a vulnerability index should be created for cities, which has been done by researchers in many countries and cities, but there is no universal definition how they should be created. One method may be to compare the spatial relationships between different variables, e.g. socioeconomic, demographic, built-in and biophysical environments, health status (Klein Rosenthal, Kinney, and Metzger 2014). The methods used are often based on principal component analysis (PCA) by analysing existing statistical data (Reid et al. 2009; Nayak et al. 2018) or risk assessment methodology (PapathomaKoehle et al. 2016).

In the future, we want to develop a solution that uses the results of dynamic simulations beyond the objective analysis of available statistical data. The concept plan of this method is shown in Figure 12. We can distinguish 4 major groups: 1 st is the climate, where want to take into account the urban heat island effect, and not only the available meteorological data, but also the microclimate. Secondly, we need to evaluate the current statistical data by considering numerous socio-economic factors. Example include death rates, age and health status, education. Thirdly, analysing the results of dynamic simulations by making a building typology for Budapest and evaluating the behaviour and overheating of the buildings. The fourth part of the analysis is to examine the wider environment of buildings, considering the proximity of air-conditioned community spaces and available transportations.

Data processing (hazard, impact, visualization)
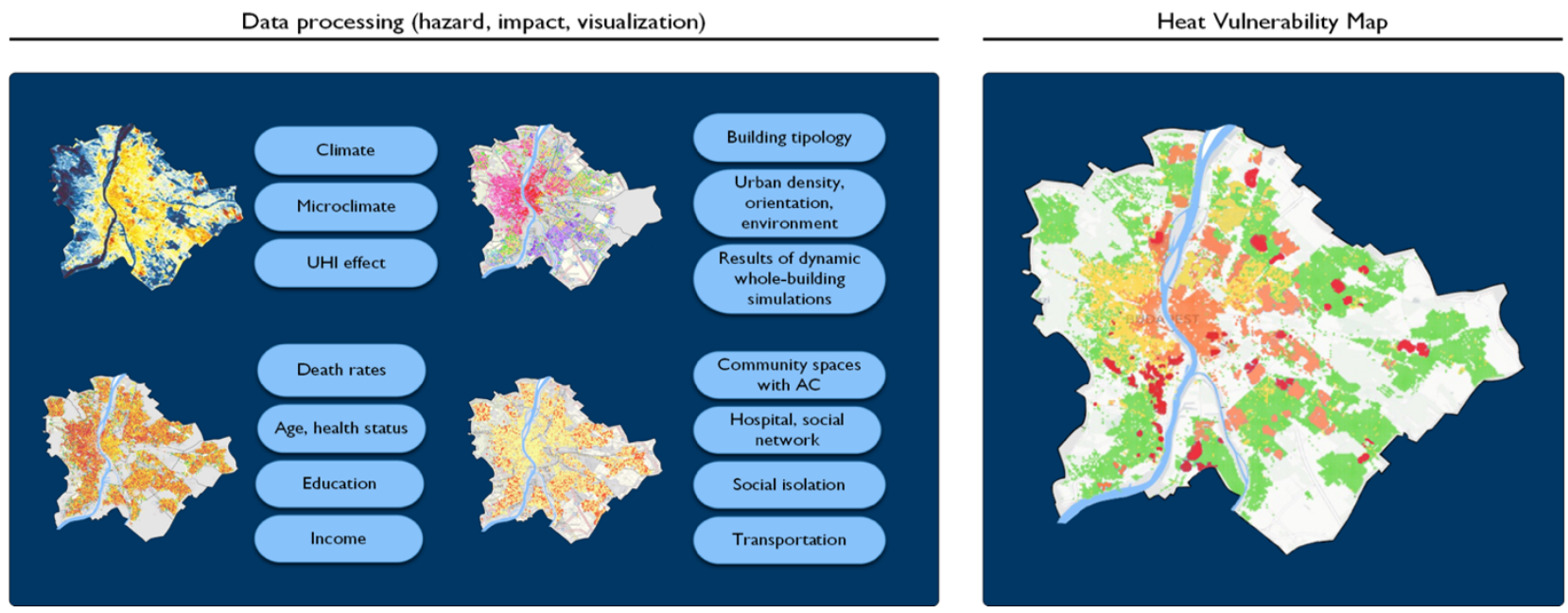

Figure 12: Creation of HVI map for Budapest (concept plan) 


\section{Conclusion}

The research has greatly contributed to the assessment of the condition of nursing homes in Budapest. The completed questionnaires allowed us to get to know elderly homes, experiences and the methods used during the summer. According to the results, this group of buildings is indeed one of the most vulnerable. Many buildings have been retrofitted, but most of the occupants are not satisfied with the internal temperature in the summer. The database created during the research can help to create a heat vulnerability index for Budapest.

With the help of the dynamic simulations, we determined the main parameters that play a major role in reducing the internal air temperature during summer. According to study, the value of the overheating indicator in the case of insulated buildings increased, to a varying extent (68-86\% and $12 \%$, depending on the type and extent of insulation used), therefore, it is not particularly beneficial in terms of the overheating of the buildings. Another important finding is that the use of thermal insulation changes the dynamics of the overheating.

Increasing the number of overnight air-change rate significantly contributed to the reduction of internal temperature: using $41 /$ h by $36 \%$, and at $61 /$ h by $52 \%$, for the second building this reduction was $54 \%$ and $66 \%$ respectively.

The operation of the shutters also has a prominent effect, different options produced the greatest improvement in the two models. In other words, which strategy may be the most optimal for each building depends on the model.

The $\mathrm{ODH}_{26}$ indicators of the two buildings are changing at different rates with regard to future climate data. In the case of the second building, the initial low value increases to a greater extent for 2050 and 2100 , which may be due to the higher thermal mass. In warmer climates, the warmed-up building can cool down more slowly and to a lesser extent.

It is definitely worth analysing buildings with a dynamic building energy simulation tool that can handle user habits in a more detailed way, because as long as there is no cooling system in the building, user habits are the variables that can be used to minimize summer overheating. Furthermore, it may be interesting to analyse buildings with air-conditioning, as it can be an important parameter in reducing the internal temperature. According to the interviews that were conducted, at least the cooling of communal spaces would be seen as essential.

\section{Acknowledgement}

The publication of the work reported herein has been supported by ETDB at BME. Project FK 128663 has been implemented with the support provided from the National Research, Development and Innovation Fund of Hungary, financed under the FK_18 funding scheme.

\section{References}

Antretter, Florian, Fabian Sauer, Teresa Schöpfer, and Andreas Holm. 2011. "Validation of a Hygrothermal Whole Building Simulation
Software." Ashrae Standard, 14-16.

Arbuthnott, Katherine, Shakoor Hajat, Clare Heaviside, and Sotiris Vardoulakis. 2016. "Changes in Population Susceptibility to Heat and Cold over Time: Assessing Adaptation to Climate Change." Environmental Health: A Global Access Science Source 15 (S1).

Artmann, N., H. Manz, and P. Heiselberg. 2008. "Parameter Study on Performance of Building Cooling by Night-Time Ventilation." Renewable Energy 33 (12): 2589-98.

Atkinson, James, Yves Chartier, Carmen Lúcia PessoaSilva, Paul Jensen, Yuguo Li, and Wing-Hong Seto. 2009. "Natural Ventilation for Infection Control in Health-Care Settings."

"BM Országos Katasztrófavédelmi Főigazgatóság." 2018.http://www.katasztrofavedelem.hu/index2.ph p?pageid=lakossag_kattipus_hoseg_tanacs.

Bunker, Aditi, Jan Wildenhain, Alina Vandenbergh, Nicholas Henschke, Joacim Rocklöv, Shakoor Hajat, and Rainer Sauerborn. 2016. "Effects of Air Temperature on Climate-Sensitive Mortality and Morbidity Outcomes in the Elderly; a Systematic Review and Meta-Analysis of Epidemiological Evidence." EBioMedicine 6: 258-68.

Dodoo, Ambrose, and Leif Gustavsson. 2016. "Energy Use and Overheating Risk of Swedish Multi-Storey Residential Buildings under Different Climate Scenarios." Energy 97: 534-48.

Fosas, Daniel, David A. Coley, Sukumar Natarajan, Manuel Herrera, Miguel Fosas de Pando, and Alfonso Ramallo-Gonzalez. 2018. "Mitigation versus Adaptation: Does Insulating Dwellings Increase Overheating Risk?" Building and Environment 143 (July): 740-59.

Guo, Chao Yu, Wen Chi Pan, Mu Jean Chen, Chen Wei Tsai, Nai Tzu Chen, and Huey Jen Su. 2014. "When Are We Most Vulnerable to Temperature Variations in a Day?" PLoS ONE 9 (12): 1-13.

Holstein, Josiane, Florence Canouï-Poitrine, Anke Neumann, Eric Lepage, and Alfred Spira. 2005. "Were Less Disabled Patients the Most Affected by 2003 Heat Wave in Nursing Homes in Paris, France?" Journal of Public Health 27 (4): 359-65.

Ishigami, Ai, Shakoor Hajat, R. Sari Kovats, Luigi Bisanti, Magda Rognoni, Antonio Russo, and Anna Paldy. 2008. "An Ecological Time-Series Study of Heat-Related Mortality in Three European Cities." Environmental Health: A Global Access Science Source 7: 1-7.

Kendrovski, Vladimir, Michela Baccini, Gerardo Sanchez Martinez, Tanja Wolf, Elizabet Paunovic, and Bettina Menne. 2017. "Quantifying Projected Heat Mortality Impacts under 21st-Centurywarming Conditions for Selected European Countries." 
International Journal of Environmental Research and Public Health 14 (7).

Klein Rosenthal, Joyce, Patrick L. Kinney, and Kristina B. Metzger. 2014. "Intra-Urban Vulnerability to Heat-Related Mortality in New York City, 19972006." Health and Place 30: 45-60.

Klenk, Jochen, Clemens Becker, and Kilian Rapp. 2010. "Heat-Related Mortality in Residents of Nursing Homes." Age and Ageing 39 (2): 245-52.

Lakatos, Mónika, Gabriella Szépszó, Zita Bihari, Ilona Krüzselyi, Péter Szabó, Judit Bartholy, Rita Pongrácz, Ildikó Pieczka, and Csaba Torma. 2012. "Éghajlati Szélsőségek Változásai Magyarországon : Közelmúlt És Jövő."

Liss, Alexander, Ruiruo Wu, Kenneth Kwan Ho Chui, and Elena N. Naumova. 2017. "Heat-Related Hospitalizations in Older Adults: An Amplified Effect of the First Seasonal Heatwave." Scientific Reports 7 (January): 1-14.

Marmor, Michael. 1978. "Heat Wave Mortality in Nursing Homes." Environmental Research 17 (1): 102-15.

Nayak, S. G., S. Shrestha, P. L. Kinney, Z. Ross, S. C. Sheridan, C. I. Pantea, W. H. Hsu, N. Muscatiello, and S. A. Hwang. 2018. "Development of a Heat Vulnerability Index for New York State." Public Health 161: 127-37.

Papathoma-Koehle, Maria, Catrin Promper, Roxana
Bojariu, Roxana Cica, András Sik, Kinga Perge, Peter László, et al. 2016. “A Common Methodology for Risk Assessment and Mapping for South-East Europe: An Application for Heat Wave Risk in Romania." Natural Hazards 82: 89-109.

Pyrgou, Andri, Veronica Lucia Castaldo, Anna Laura Pisello, Franco Cotana, and Mattheos Santamouris. 2017. "On the Effect of Summer Heatwaves and Urban Overheating on Building Thermal-Energy Performance in Central Italy." Sustainable Cities and Society 28: 187-200.

Reid, Colleen E., Marie S. O’Neill, Carina J. Gronlund, Shannon J. Brines, Daniel G. Brown, Ana V. DiezRoux, and Joel Schwartz. 2009. "Mapping Community Determinants of Heat Vulnerability." Environmental Health Perspectives 117 (11): 1730-36.

Seth, Anand K, Theodore Cohen, Dennis E Shaughnessy, George A Freeman, Michael Patrick Sheerin, Robert J Weber, Gerald L Hendrickson, et al. 2008. ASHRAE Standard: Ventilation of Health Care Facilities. American Society of Heating, Refrigerating and Air-Conditioning Engineers.

Wu, Connor Y.H., Benjamin F. Zaitchik, and Julia M. Gohlke. 2018. "Heat Waves and Fatal Traffic Crashes in the Continental United States." Accident Analysis and Prevention 119 (April): 195-201. 